\title{
Anaplastic Large Cell Lymphoma Mimicking Fibrosing Mediastinitis
}

\author{
Masato Taki ${ }^{1}$, Shinya Inada ${ }^{2}$, Ryo Ariyasu ${ }^{1}$, Yoshinobu Konishi ${ }^{2}$, Natsumi Okamoto ${ }^{1}$, \\ Masanori Yoshida ${ }^{1}$, Hiroaki Nagano ${ }^{1}$, Kenji Hanaoka ${ }^{1}$, Kazuhiko Nakagawa ${ }^{1}$, \\ Yasukiyo Nakamura ${ }^{1}$, Chie Yoshimura ${ }^{1}$, Toshiaki Wakayama ${ }^{1}$, Yasuo Nishizaka ${ }^{1}$, \\ Tomoko Wakasa ${ }^{3}$, Mitsuru Tsudo ${ }^{2}$ and Ryoichi Amitani ${ }^{1}$
}

\begin{abstract}
Fibrosing mediastinitis is rare. One type of this disease is idiopathic fibrosing mediastinitis. It is necessary to rule out malignancy in order to accurately diagnose fibrosing mediastinitis. We herein report a case of anaplastic large cell lymphoma diagnosed three months after a preliminary diagnosis of fibrosing mediastinitis. Glucocorticoid therapy was not successful in controlling disease progression. Immediately after initiating chemotherapy for lymphoma, the patient's symptoms improved dramatically and the mediastinal lesion decreased in size. Although few similar cases have been reported, hidden malignancy may present as fibrosing mediastinitis. Therefore, physicians should consider the probability of malignancy in patients with fibrosing mediastinitis because treatments may vary accordingly.
\end{abstract}

Key words: fibrosing mediastinitis, anaplastic large cell lymphoma, glucocorticoid therapy, CHOP chemotherapy

(Intern Med 52: 2645-2651, 2013)

(DOI: 10.2169/internalmedicine.52.1016)

\section{Introduction}

Fibrosing mediastinitis is known as sclerosing mediastinitis or mediastinal fibrosis. It is characterized by fibroblast proliferation and inflammatory cell infiltration and may cause compression of the airways, great vessels and other mediastinal structures (1). Only a few etiologies, including histoplasmosis, have so far been suggested, and only a few cases of idiopathic fibrosing mediastinitis have been reported. Therefore, fibrosing mediastinitis is not completely understood. Histologically, malignancy occasionally mimics fibrosing mediastinitis. Consequently, fibrosing mediastinitis cannot be diagnosed unless malignancy is ruled out. However, malignancy may only become evident after fibrosing mediastinitis has been diagnosed.

We herein present the case of a woman with anaplastic large cell lymphoma that was initially diagnosed as fibrosing mediastinitis. We discuss the necessity of providing active follow-up for fibrosing mediastinitis and the possibility that a treatment change may be required if malignant disease is revealed after the initial diagnosis.

\section{Case Report}

The patient was a 43-year-old woman without any history of malignancy. She had not travelled abroad within the past 10 years. She had developed a nonproductive cough one month earlier, for which she visited our hospital. Chest radiography showed decreased permeability in the right lower lung field and computed tomography (CT) revealed a diffuse mediastinal lesion and atelectasis in the right middle lobe (Fig. 1). ${ }^{18}$ F-fluorodeoxyglucose-positron emission tomography (FDG-PET) imaging showed hypermetabolic mediastinal lesions; no other hypermetabolic lesions were observed (Fig. 2).

\footnotetext{
${ }^{1}$ Department of Respiratory Medicine, Osaka Red Cross Hospital, Japan, ${ }^{2}$ Department of Hematology, Osaka Red Cross Hospital, Japan and ${ }^{3}$ Department of Pathology, Osaka Red Cross Hospital, Japan

Received for publication May 17, 2013; Accepted for publication July 2, 2013

Correspondence to Dr. Masato Taki, qyfjy370qyfjy370@yahoo.co.jp
} 

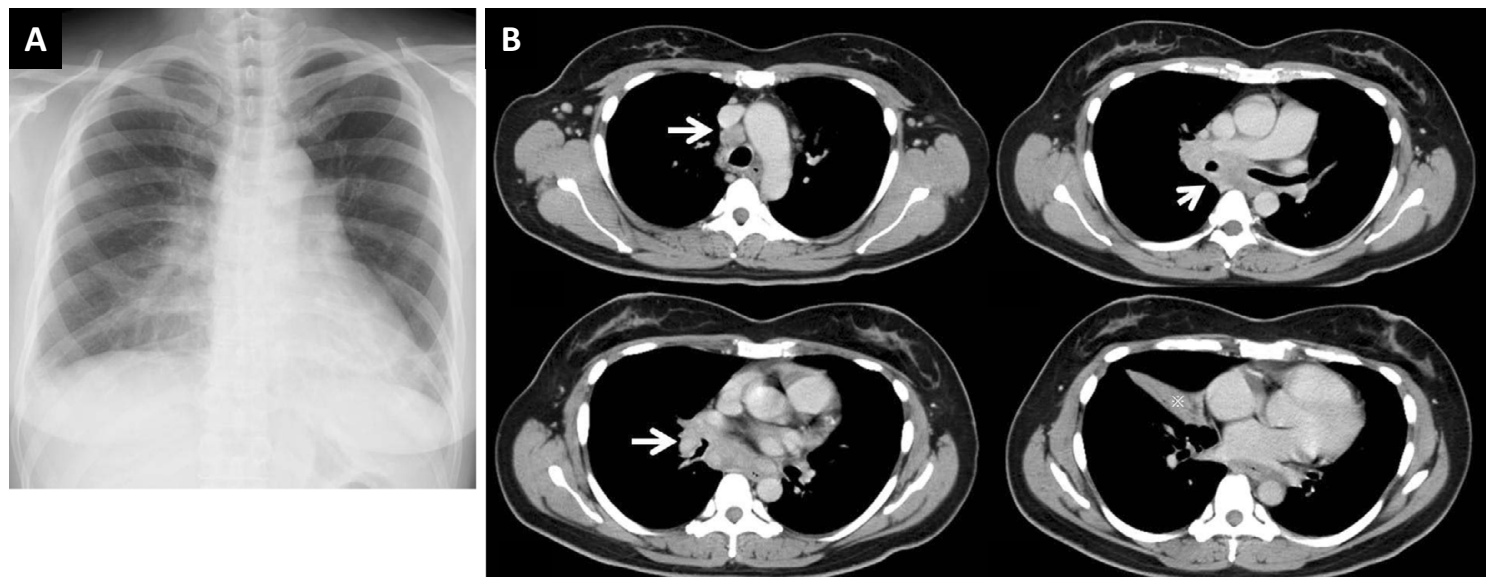

Figure 1. A) A chest radiograph obtained on presentation showing decreased permeability in the right lower lung field caused by atelectasis. B) A chest computed tomography scan obtained on presentation showing a diffuse mediastinal lesion (arrows) and atelectasis of the right middle lobe (※).

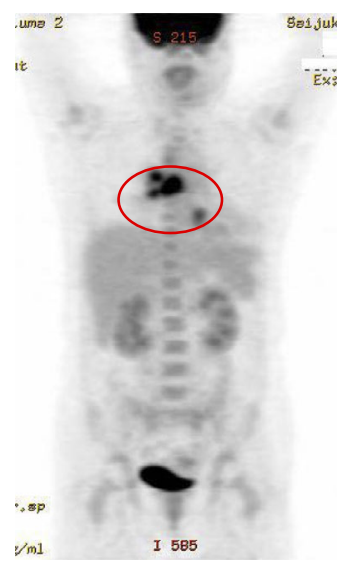

Figure 2. ${ }^{18}$ F-FDG PET showing hypermetabolic mediastinal lesions.

The laboratory findings of the patient on presentation included increased total white blood cell (WBC) and neutrophil counts and an increased C-reactive protein level, as shown in Table. The levels of soluble interleukin-2 receptor and lung cancer markers as well as fungal antigens and immunoglobulin were within the normal ranges.

Bronchoscopy revealed that the peripheral bronchial mucosa from the right main bronchus was diffusely irregular and that the orifice of the right middle lobe was nearly obstructed (Fig. 3). Transbronchial samples of the irregular bronchial mucosa and a lymph node of the tracheal bifurcation were obtained twice using bronchoscopy. However, a diagnosis could not be made because the samples showed only a few normal lymphocytes and no malignant cells. The CT and bronchoscopy findings suggested malignancy; therefore, a biopsy was performed via video-assisted thoracic surgery. Because the diffuse mediastinal lesion was extremely hard, it could not be separated from the surrounding structures, such as the right pulmonary artery and right bronchus. The mediastinal lesion was partially resected; the surgical samples showed only fibrosis (Fig. 4A), and the patient was diagnosed with fibrosing mediastinitis. Her symptoms pro- gressed, and systemic glucocorticoid therapy was initiated. Consequently, the diffuse mediastinal lesion exhibited a slight decrease in size.

Three weeks after the initiation of glucocorticoid therapy and approximately three months after the first visit, the patient experienced pain in the right side of her neck. Her WBC count had increased from 12,950 to 30,310 cells $/ \mu \mathrm{L}$ (neutrophils, $82.5 \%$; basophils, $0.5 \%$; lymphocytes, $12.0 \%$; monocytes, $4.5 \%$; metamyelocytes, $0.5 \%$ ). CT revealed swelling of the right cervical lymph nodes (Fig. 5). Tissue samples obtained from the right cervical lymph nodes under local anesthesia revealed a few chronic inflammatory cells, fibrosis and no malignant cells. Subsequently, the patient experienced back pain. The diffuse mediastinal lesion had increased in size, and she developed swelling of the celiac lymph nodes (Fig. 5). Therefore, a large portion of the patient's right cervical lymph nodes were resected under general anesthesia. The right cervical lymph nodes demonstrated hardness similar to that of the mediastinal lesion, and malignant cells were eventually detected in the nodes (Fig. 4B, C). Although Hodgkin's lymphoma was suspected on Hematoxylin and Eosin staining, immunohistochemical staining demonstrated that the malignant cells were positive for anaplastic lymphoma kinase (ALK) and CD30 (Ki-1) (Fig. 4D, E). Accordingly, ALK-positive anaplastic large cell lymphoma was diagnosed approximately five months after the first visit.

Doxorubicin, bleomycin, vinblastine and dacarbazine (ABVD) chemotherapy for Hodgkin's lymphoma was administered immediately before the results of immunohistochemical staining were obtained because the right main bronchus was nearly obstructed. A few days later, the nonproductive cough disappeared. The patient's WBC count decreased from 34,300 cells/per $\mu \mathrm{L}$ (neutrophils, $90.0 \%$; lymphocytes, $6.0 \%$; monocytes, $4.0 \%$ ) to 8,190 cells/per $\mu \mathrm{L}$ (neutrophils, 75.4\%; eosinophils, 0.2\%; basophils, 0.1\%; lymphocytes, $23.4 \%$; monocytes, $0.9 \%$ ) after only three days of chemotherapy initiation. The diffuse mediastinal lesion 
Table. Laboratory Findings on Presentation

\begin{tabular}{|c|c|c|c|c|c|}
\hline \multicolumn{2}{|c|}{$<$ Complete Blood Cell Counts $>$} & \multicolumn{3}{|c|}{ <Serological Studies > } & normal range \\
\hline WBC & $11,200 / \mu \mathrm{L}$ & CEA & 1.0 & ng/mL & $0-5$ \\
\hline Neut & $81.4 \%$ & SLX & 30 & $\mathbf{U} / \mathbf{m L}$ & $0-38$ \\
\hline Eosino & $0.5 \%$ & CYFRA & $<1.0$ & $\mathbf{n g} / \mathbf{m L}$ & $0-3.5$ \\
\hline Baso & $0.1 \%$ & NSE & 10.9 & $\mathbf{n g} / \mathbf{m L}$ & 0 - 16.3 \\
\hline Lymph & $13.7 \%$ & ProGRP & 22.1 & $\mathrm{pg} / \mathrm{mL}$ & $0-80.9$ \\
\hline Mono & $4.3 \%$ & & & & \\
\hline RBC & $422 \times 10^{4} / \mu \mathrm{L}$ & Soluble & & & \\
\hline $\mathbf{H b}$ & $11.1 \mathrm{~g} / \mathrm{dL}$ & Interleukin-2 & & & \\
\hline Het & $33.8 \%$ & (IL-2) receptor & 311 & $\mathbf{U} / \mathbf{m L}$ & $145-519$ \\
\hline PLT & $54.3 \times 10^{4} / \mu \mathrm{L}$ & $\beta$-HCG & $<5$ & $\mathbf{m I U} / \mathbf{m L}$ & \\
\hline \multicolumn{2}{|c|}{$<$ Blood Chemistry $>$} & AFP & 2.9 & ng/mL & $0-10$ \\
\hline $\mathbf{T P}$ & $8.0 \mathrm{~g} / \mathrm{dL}$ & Aspergillus & & & \\
\hline Alb & $4.1 \mathrm{~g} / \mathrm{dL}$ & antigen & $(-)$ & & \\
\hline AST & $35 \mathrm{IU} / \mathrm{L}$ & Cryptococcal & & & \\
\hline ALT & 36 IU/L & antigen & $(-)$ & & \\
\hline T-Bil & $0.6 \mathrm{mg} / \mathrm{dL}$ & & & & \\
\hline BUN & $7.0 \mathrm{mg} / \mathrm{dL}$ & IgG & 1,772 & $\mathrm{mg} / \mathrm{dL}$ & 870 - 1,700 \\
\hline Cre & $0.51 \mathrm{mg} / \mathrm{dL}$ & IgG4 & 75.8 & $\mathrm{mg} / \mathrm{dL}$ & \\
\hline $\mathbf{N a}$ & $137 \mathrm{mEq} / \mathrm{L}$ & IgA & 256 & $\mathrm{mg} / \mathrm{dL}$ & $110-410$ \\
\hline $\mathbf{K}$ & $3.5 \mathrm{mEq} / \mathrm{L}$ & IgM & 156 & $\mathrm{mg} / \mathrm{dL}$ & $35-220$ \\
\hline CRP & $7.6 \mathrm{mg} / \mathrm{dL}$ & & & & \\
\hline
\end{tabular}
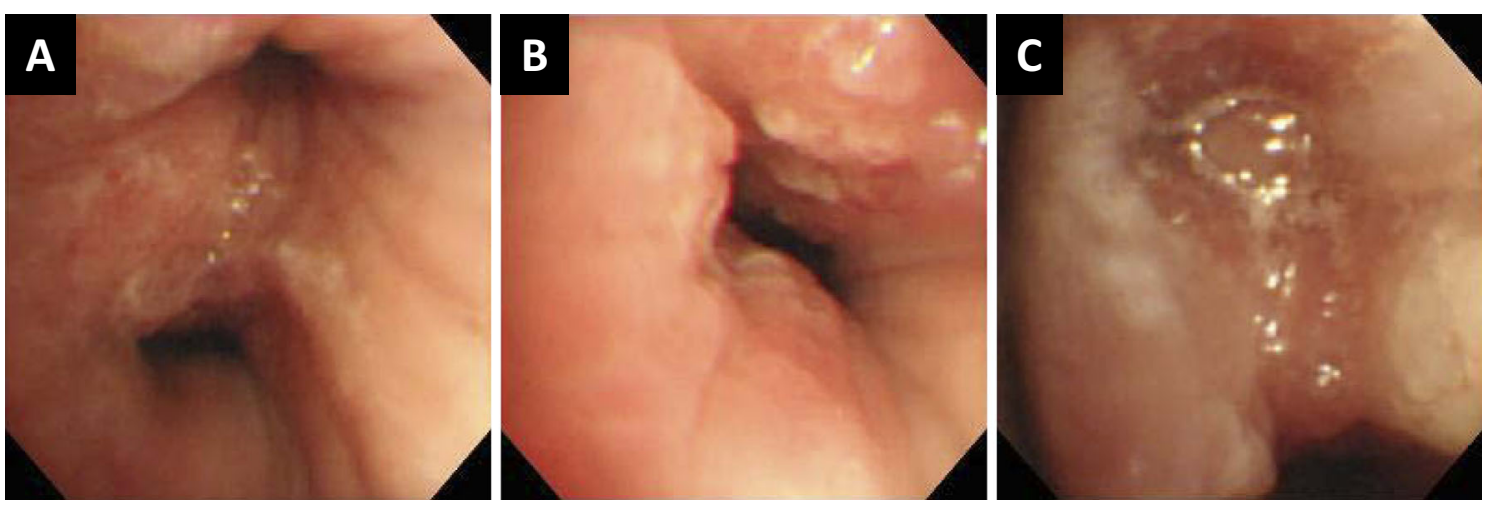

Figure 3. A) Bronchial mucosa appearing diffusely irregular at the right second carina. B) In addition to the mucosal irregularity, the bronchus intermedius appears stenosed. C) Occlusion of the orifice of the right middle lobe.

dramatically decreased in size, and chest radiography and CT demonstrated that the atelectasis of the right middle lobe had resolved (Fig. 6). After the immunohistochemical staining revealed a definitive diagnosis, the ABVD chemotherapy was switched to cyclophosphamide, doxorubicin, vincristine and prednisone (CHOP) chemotherapy, which is more commonly used to treat ALK-positive anaplastic large cell lymphoma. The patient was discharged without an exacerbation of symptoms or any major side effects of chemotherapy and subsequently treated with CHOP chemotherapy.

\section{Discussion}

Fibrosing mediastinitis is a rare disorder characterized by excessive mediastinal fibrosis. It is caused by Histoplasma capsulatum infection, tuberculosis, mediastinal radiation or Aspergillus (2-4). An idiopathic form of fibrosing mediastinitis has also been described (5).

In the United States, most cases are considered to represent an immune-mediated hypersensitivity response to $H$. capsulatum infection (6). However, in Japan, where histoplasmosis does not exist, idiopathic fibrosing mediastinitis has primarily been reported $(7,8)$.

In a series of 71 patients with fibrosing mediastinitis and H. capsulatum infection, 21 patients died during the followup (9). The mean duration between the development of symptoms and death in these patients was less than six years. Cor pulmonale or respiratory failure due to recurrent infection, bronchial obstruction or hemoptysis are the most common causes of death.

It was recently reported that fibrosing mediastinitis may be associated with immunoglobulin G4 (IgG4)-related disease (10). In 1993, a case of Sjogren's syndrome accompanied by lymphadenopathy and IgG4 hypergammaglobulinemia was reported (11). Subsequently, fibrosing mediastinitis and retroperitoneal fibrosis, including autoimmune pancreatitis, primary sclerosing cholangitis and orbital sclerosing sialadenitis, were identified in patients with IgG4-related disease $(10,12,13)$.

There is no established treatment for idiopathic fibrosing 

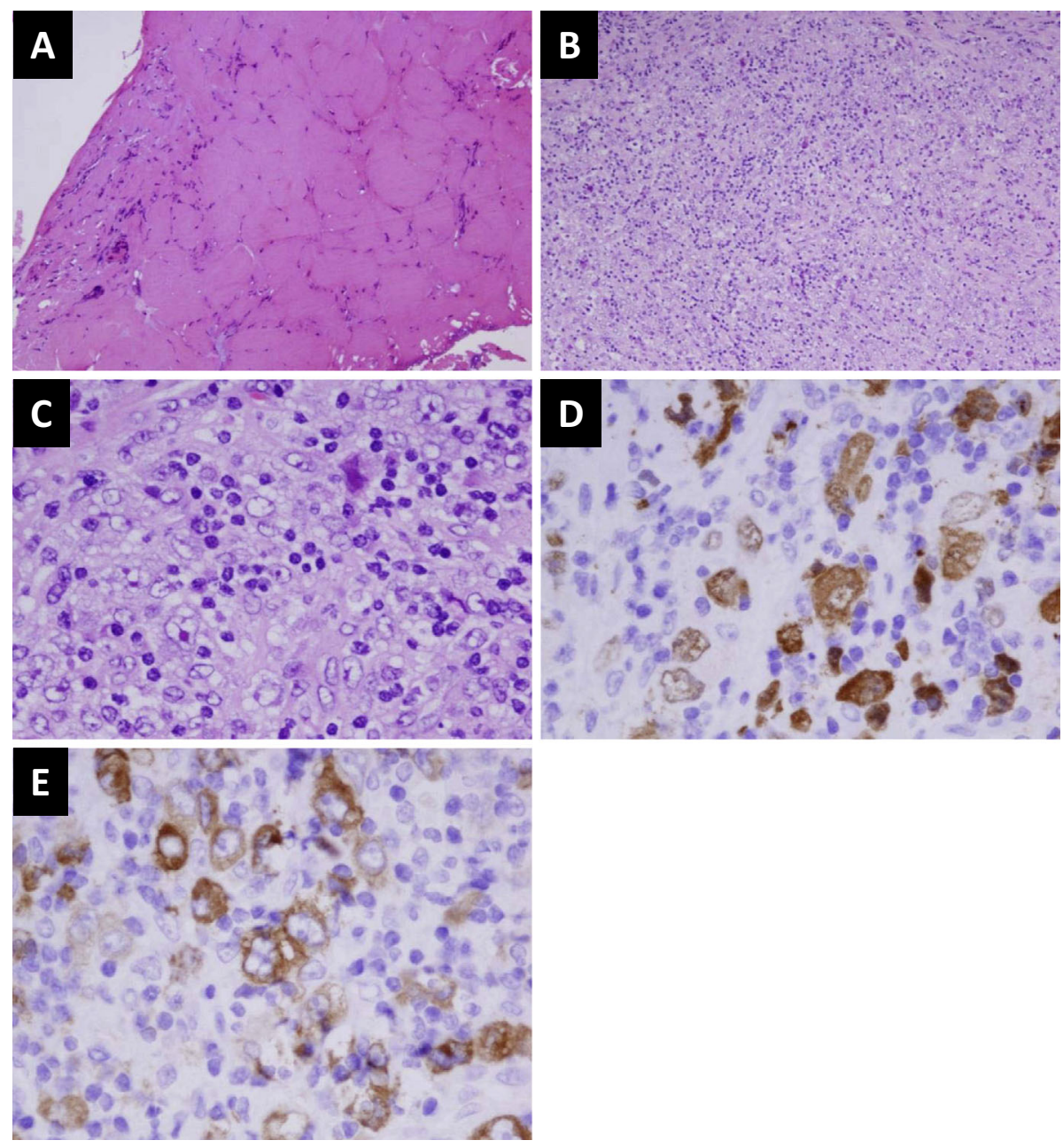

Figure 4. A) Hematoxylin and Eosin (H\&E) staining of the mediastinum showing fibrosis; original magnification, $\times 40$. B, C) H\&E staining of a right cervical lymph node biopsy specimen showing malignant lymphoma cells; original magnification, $\times 100, \times 400$. D) Immunohistochemical staining demonstrating that the malignant lymphoma cells are positive for anaplastic lymphoma kinase; original magnification, $\times 400$. E) Immunohistochemical staining demonstrating that the malignant lymphoma cells are positive for CD30; original magnification, $\times \mathbf{4 0 0}$.

mediastinitis. However, glucocorticoid therapy and surgical intervention may be employed $(14,15)$. Fibrosing mediastinitis associated with histoplasmosis commonly exhibits a localized radiographic pattern such as a mass (16). In contrast, fibrosing mediastinitis with an idiopathic or noninfectious etiology commonly demonstrates a diffuse radiographic pattern, as seen in our case. Patients with diffuse patterns may respond more favorably to glucocorticoid therapy (14). Surgery is occasionally performed as palliative therapy to relieve airway, vascular and esophageal obstruction; however, the presence of extensive fibrosis, calcification and collateral vessels makes performing surgery difficult. Three deaths occurred during the early postoperative period in a series of 18 patients with fibrosing mediastinitis secondary to histoplasmosis (15).

According to the 2008 World Health Organization (WHO) classification, anaplastic large cell lymphoma is classified under the mature T-cell and NK-cell group of neoplasms (17). Anaplastic large cell lymphoma may be primar- ily cutaneous or systemic. Primary cutaneous anaplastic large cell lymphoma is confined to the skin and does not exhibit translocation involving ALK. In contrast, primary systemic anaplastic large cell lymphoma may show translocation. Systemic ALK-positive anaplastic large cell lymphoma has a significantly better prognosis than systemic ALKnegative anaplastic large cell lymphoma (18). ALK-positive anaplastic large cell lymphoma has a 5-year survival rate of approximately $70 \%$ (19). CHOP chemotherapy is the standard therapy for anaplastic large cell lymphoma.

Our patient underwent repeated bronchoscopy and a surgical biopsy. Only mediastinal fibrosis was detected, leading to a diagnosis of fibrosing mediastinitis. The serum $\mathrm{IgG} 4$ level was within the normal range, and the histology did not show storiform cell-rich fibrosis or obliterative phlebitis, which is typical of IgG4-related disease (10). Subsequently, the patient was diagnosed with idiopathic fibrosing mediastinitis. There were no contradictions in the imaging or pathological findings. Because it was difficult to resect the 

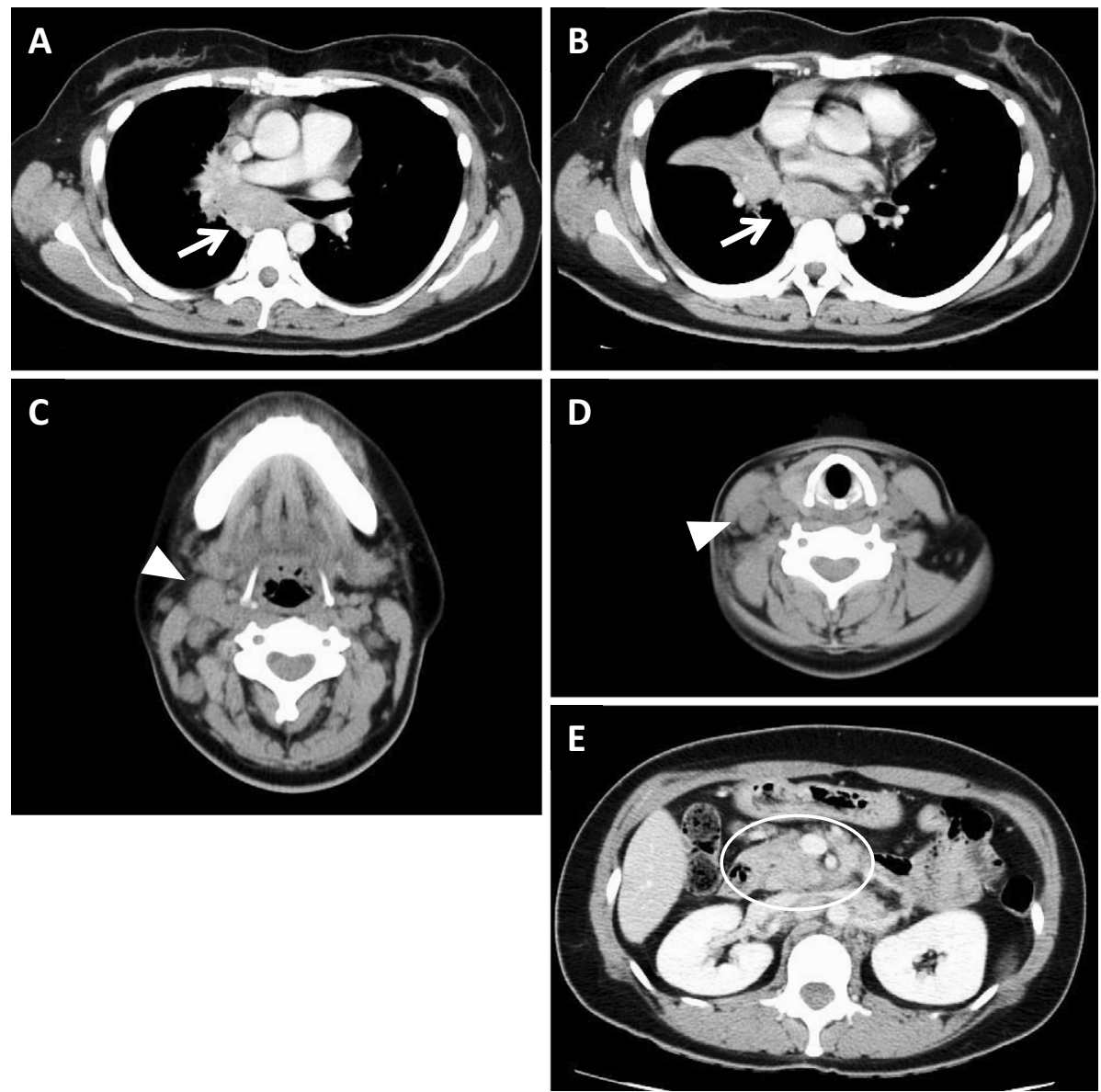

Figure 5. A, B) The mediastinal lesion is enlarged (arrows). C, D) Swollen right lymph nodes (arrow-heads). E) Swelling of several celiac lymph nodes (ellipse).
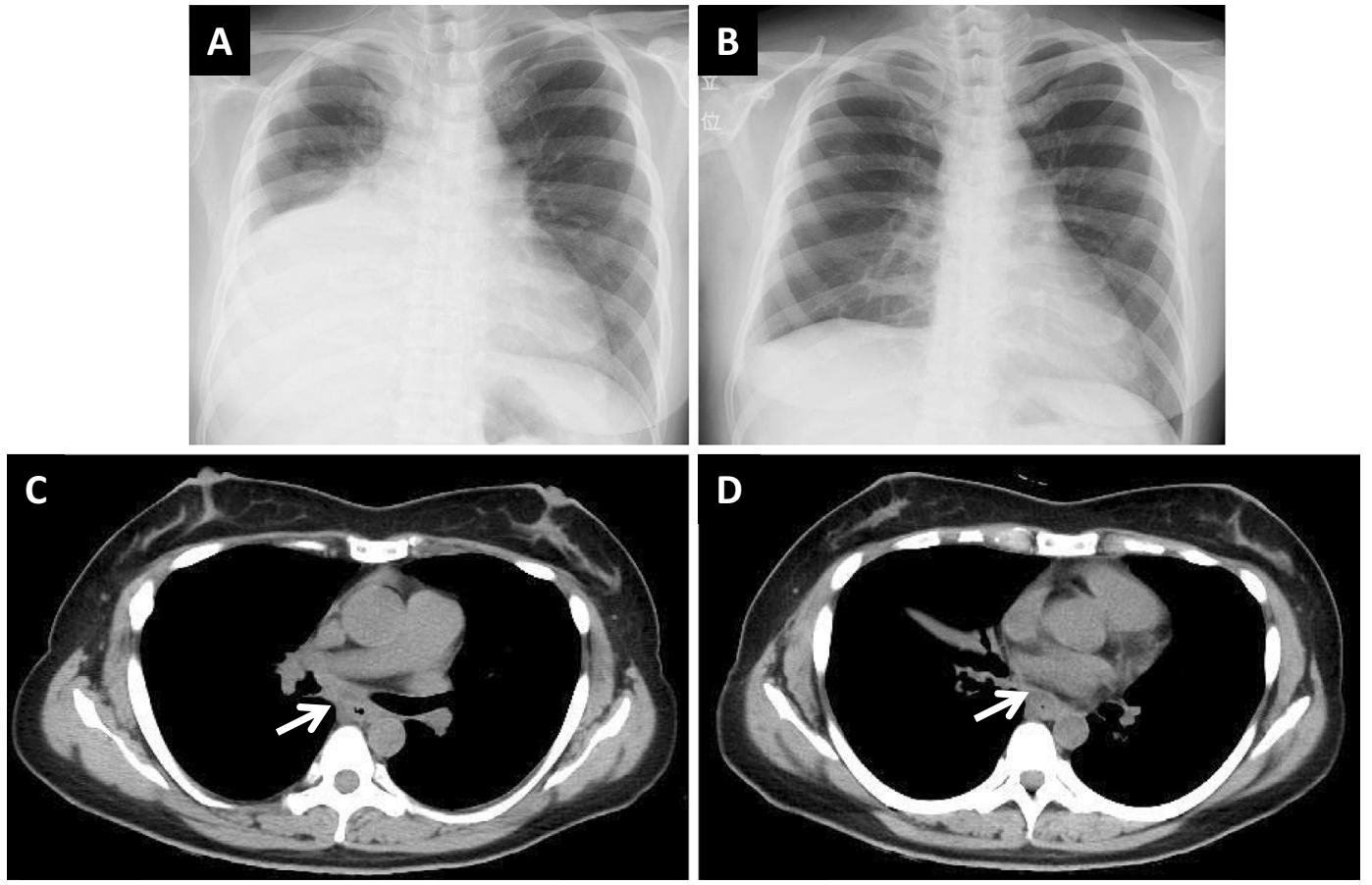

Figure 6. A) A chest radiograph showing atelectasis in the lower lung field one day before the initiation of chemotherapy. B) The atelectasis disappeared three days after the initiation of chemotherapy. C, D) The mediastinal lesion decreased in size following the administration of chemotherapy (arrows). 
lesion from the surrounding structures in our patient, we therefore chose to administer glucocorticoid therapy.

However, swelling of the right cervical and celiac lymph nodes was observed following the initiation of glucocorticoid therapy; therefore, we decided to explore other potential etiologies and performed a cervical lymph node biopsy. Finally, we confirmed that a hidden malignancy, i.e., anaplastic large cell lymphoma, was presenting as fibrosing mediastinitis.

To our knowledge, there have been no reports of anaplastic large cell lymphoma that was confused with fibrosing mediastinitis; therefore, this is the first report of anaplastic large cell lymphoma mimicking fibrosing mediastinitis. Malignant neoplasms often induce fibrosis. However, there are few malignant cases that mimic fibrosing mediastinitis. Two cases of breast cancer and a case of Hodgkin's lymphoma have been reported (20-22). With regard to retroperitoneal fibrosis associated with fibrosing mediastinitis, several case reports, including a case of anaplastic large cell lymphoma, have described malignant lymphoma accompanied by retroperitoneal fibrosis $(23,24)$. Fibrosis is usually observed in the pathogenesis of nodular sclerosing classical Hodgkin's lymphoma (25). A variant of anaplastic large cell lymphoma resembles Hodgkin's lymphoma of the nodular sclerosis type, and both are positive for CD30 (Ki-1) on immunohistochemical staining (26). Given these facts, it is reasonable that anaplastic large cell lymphoma provoked fibrosing mediastinitis in our case.

Anaplastic large cell lymphoma may have existed beyond the extent of resection during the surgical biopsy of the mediastinum. Therefore, an open chest biopsy rather than video-assisted thoracic surgery should have been performed because the mediastinal lesion was extremely hard. However, considering that a transbronchial aspiration biopsy of the lymph node at the bronchial bifurcation, a transbronchial biopsy of the bronchial mucosa and a surgical biopsy of the tissues outside the bronchial tract were performed, it is unlikely that many malignant cells existed at the time. Before the right cervical and celiac lymph node swelling developed, making a definitive diagnosis would have been difficult if malignant cells had been present in the mediastinum. The difficulty of the diagnosis was confirmed in this patient by the fact that the malignancy was not verified based on the results of the right cervical lymph node biopsy performed under local anesthesia.

Glucocorticoid therapy slightly decreased the size of the mediastinal lesion, which indicated that the malignant lymphoma was controlled temporarily. As a result, chemotherapy for malignant lymphoma was able to rapidly decrease the size of the mediastinal lesion and cervical lymph nodes. It is important to distinguish between fibrosing mediastinitis and malignancy because the required treatments are significantly different and the prognosis of the patient may vary accordingly.

In conclusion, hidden malignancy should be considered and carefully ruled out in the diagnosis of fibrosing medi- astinitis. In addition, malignancy may develop during follow-up of patients with fibrosing mediastinitis. To yield a sufficiently sized sample, an open biopsy may be needed because malignant lesions with severe fibrosis are extremely hard. To accurately differentiate both conditions, it is necessary to investigate more cases of malignancy mimicking fibrosing mediastinitis.

The authors state that they have no Conflict of Interest (COI).

\section{References}

1. Feigin DS, Eggleston JC, Siegelman SS. The multiple roentgen manifestations of sclerosing mediastinitis. Johns Hopkins Med J 144: 1-8, 1979.

2. Loyd JE, Tillman BF, Atkinson JB, Des Prez RM. Mediastinal fibrosis complicating histoplasmosis. Medicine (Baltimore) 67: 295$310,1988$.

3. Morrone N, Gama e Silva Volpe VL, Dourado AM, Mitre F, Coletta EN. Bilateral pleural effusion due to mediastinal fibrosis induced by radiotherapy. Chest 104: 1276-1278, 1993.

4. Ahmad M, Weinstein AJ, Hughes JA, Cosgrove DE. Granulomatous mediastinitis due to Aspergillus flavus in a nonimmunosuppressed patient. Am J Med 70: 887-890, 1981.

5. Worrell JA, Donnelly EF, Martin JB, Bastarache JA, Loyd JE. Computed tomography and the idiopathic form of proliferative fibrosing mediastinitis. J Thorac Imaging 22: 235-240, 2007.

6. Peikert T, Colby TV, Midthun DE, et al. Fibrosing mediastinitis: clinical presentation, therapeutic outcomes, and adaptive immune response. Medicine (Baltimore) 90: 412-423, 2011.

7. Kinugasa S, Tachibana S, Kawakami M, Orino T, Yamamoto R, Sasaki S. Idiopathic mediastinal fibrosis: report of a case. Surg Today 28: 335-338, 1998.

8. Ichimura $\mathrm{H}$, Ishikawa $\mathrm{S}$, Yamamoto $\mathrm{T}$, et al. Effectiveness of steroid treatment for hoarseness caused by idiopathic fibrosing mediastinitis: report of a case. Surg Today 36: 382-384, 2006.

9. Loyd JE, Tillman BF, Atkinson JB, Des Prez RM. Mediastinal fibrosis complicating histoplasmosis. Medicine (Baltimore) 67: 295310, 1988.

10. Peikert T, Shrestha B, Aubry MC, et al. Histopathologic overlap between fibrosing mediastinitis and IgG4-related disease. Int $\mathbf{J}$ Rheumatol 2012: 207056, 2012.

11. Suzuki S, Kida S, Ohira Y, et al. A case of Sjögren's syndrome accompanied by lymphadenopathy and IgG4 hypergammaglobulinemia. Ryumachi 33: 249-254, 1993 (in Japanese, Abstract in English).

12. Okazaki K, Uchida K, Koyabu M, Miyoshi H, Takaoka M. Recent advances in the concept and diagnosis of autoimmune pancreatitis and IgG4-related disease. J Gastroenterol 46: 277-288, 2011.

13. Khosroshahi A, Stone JH. A clinical overview of IgG4-related systemic disease. Curr Opin Rheumatol 23: 57-66, 2011.

14. Sherrick AD, Brown LR, Harms GF, Myers JL. The radiographic findings of fibrosing mediastinitis. Chest 106: 484-489, 1994.

15. Mathisen DJ, Grillo HC. Clinical manifestation of mediastinal fibrosis and histoplasmosis. Ann Thorac Surg 54: 1053-1058, 1992.

16. Williams SM, Jones ET. General case of the day. Fibrosing mediastinitis. Radiographics 17: 1324-1327, 1997.

17. Steven H, Elias C, Nancy L, et al. WHO Classification of Tumours of Haematopoietic and Lymphoid Tissues. 4th ed. International Agency for Research on Cancer, Lyon, 2008: 12.

18. Savage KJ, Harris NL, Vose JM, et al. ALK anaplastic large-cell lymphoma is clinically and immunophenotypically different from both $\mathrm{ALK}^{+} \mathrm{ALCL}$ and peripheral T-cell lymphoma, not otherwise specified: report from the International Peripheral T-Cell Lym- 
phoma Project. Blood 111: 5496-5504, 2008.

19. Falini B, Pileri S, Zinzani PL, et al. $\mathrm{ALK}^{+}$lymphoma: clinicopathological findings and outcome. Blood 93: 2697-2706, 1999.

20. Ishibashi $H$, Ohta $S$, Hirose $M$, et al. Mediastinal recurrence of breast cancer suspecting mediastinal fibrosis. Kyobu Geka 59: 1095-1098, 2006 (in Japanese, Abstract in English).

21. Gogas J, Markopoulos C, Kouskos E, Gogas H, Kiriakou V. Metastatic retroperitoneal and mediastinal fibrosis as first sign of recurrence of breast cancer. Eur J Surg 167: 715-718, 2001.

22. Zisis C, Kefaloyannis EM, Rontogianni D, et al. Asymptomatic chest wall Hodgkin disease mimicking fibrosing mediastinitis. J Thorac Cardiovasc Surg 131: e1-e2, 2006.

23. Hatsuse M, Fuchida S, Okano A, Murakami S, Haruyama H, Shi- mazaki C. Primary retroperitoneal diffuse large B cell lymphoma with sclerosis mimicking idiopathic retroperitoneal fibrosis. Rinsho Ketsueki 53: 2018-2020, 2012.

24. Hammer ST, Jentzen JM, Lim MS. Anaplastic lymphoma kinasepositive anaplastic large cell lymphoma presenting as retroperitoneal fibrosis. Hum Pathol 42: 1810-1812, 2011.

25. Strickler JG, Michie SA, Warnke RA, Dorfman RF. The "syncytial variant" of nodular sclerosing Hodgkin's disease. Am J Surg Pathol 10: 470-477, 1986.

26. Zinzani PL, Bendandi M, Martelli M, et al. Anaplastic large-cell lymphoma: clinical and prognostic evaluation of 90 adult patients. J Clin Oncol 14: 955-962, 1996.

(C) 2013 The Japanese Society of Internal Medicine http://www.naika.or.jp/imonline/index.html 